\title{
SUB-PIXEL MINERAL MAPPING USING EO-1 HYPERION HYPERSPECTRAL DATA
}

\author{
Chandan Kumar a, *, Amba Shetty a, Simit Raval ${ }^{\mathbf{b}}$, Prashant Kumar Champatiray ${ }^{\mathbf{c}}$, Richa Sharma ${ }^{\mathbf{c}}$ \\ a Dept. of Applied Mechanics and Hydraulics, National Institute of Technology Karnataka, Mangalore 575025, India - \\ chandankumar138@gmail.com; amba_shetty@yahoo.co.in \\ b School of Mining Engineering, The University of New South Wales, Sydney NSW 2052, Australia - simit@unsw.edu.au \\ c Dept. of Geosciences and Geohazards, Indian Institute of Remote Sensing, Dehradun 248001, India - champati_ray@iirs.gov.in; \\ richa@iirs.gov.in
}

Commission VI, WG VI/4

KEY WORDS: Mineral exploration, Feature extraction, Hyper spectral, MTTCIMF algorithm, Sub-pixel

\begin{abstract}
:
This study describes the utility of Earth Observation (EO)-1 Hyperion data for sub-pixel mineral investigation using Mixture Tuned Target Constrained Interference Minimized Filter (MTTCIMF) algorithm in hostile mountainous terrain of Rajsamand district of Rajasthan, which hosts economic mineralization such as lead, zinc, and copper etc. The study encompasses pre-processing, data reduction, Pixel Purity Index (PPI) and endmember extraction from reflectance image of surface minerals such as illite, montmorillonite, phlogopite, dolomite and chlorite. These endmembers were then assessed with USGS mineral spectral library and lab spectra of rock samples collected from field for spectral inspection. Subsequently, MTTCIMF algorithm was implemented on processed image to obtain mineral distribution map of each detected mineral. A virtual verification method has been adopted to evaluate the classified image, which uses directly image information to evaluate the result and confirm the overall accuracy and kappa coefficient of $68 \%$ and 0.6 respectively. The sub-pixel level mineral information with reasonable accuracy could be a valuable guide to geological and exploration community for expensive ground and/or lab experiments to discover economic deposits. Thus, the study demonstrates the feasibility of Hyperion data for sub-pixel mineral mapping using MTTCIMF algorithm with cost and time effective approach.
\end{abstract}

\section{INTRODUCTION}

Hyperspectral sensors acquire images of earth surface in many narrow, continuous and discrete spectral bands in such a way that a complete spectral pattern of each pixel can be derived for target detection, discrimination and classification (Zadeh et al., 2013). Airborne hyperspectral sensors were extensively used in comprehensive study of earth's materials by several researchers across the globe but access to such advanced imaging systems are still challenging in developing nation such as India. However, launch of spaceborne hyperspectral sensor Earth Observation (EO)-1 in November 2000 has met the global demand of hyperspectral data for extensive range of applications. The sensor measures the energy reflected from the earth' surface in visible near infrared (VNIR) and short-wave infrared (SWIR) covering the wavelength of 400-2500 nm with 242 spectral bands at $10 \mathrm{~nm}$ and $30 \mathrm{~m}$ spectral and spatial resolution respectively (Breck, 2003). Most of the surface minerals show diagnostic spectral signature in VNIR and SWIR of electromagnetic spectrum which enables their detection on the basis on characteristics spectral signature (Hunt, 1977; Clark et al., 1999; Rowan et al., 2004; Kruse et al., 2006). The Hyperion hyperspectral sensor provides fine resolution and makes possible to detect several minerals viz. clays (illite, montmorillonite, kaolinite, and alunite), carbonates (calcite, dolomite), oxides (hematite, goethite, and jarosite), chlorites etc (Magendran and Sanjeevi, 2013; Zadeh et al., 2013). Several surface mineral mapping were carried with significant accuracy demonstrate the utility of Hyperion data (Jafari and Lewis, 2012; Kusuma et al., 2012; Farifteh et al., 2013). Most of these studies focus on full pixel mineral detection or mapping by considering pixels as pure which may not be the case on the ground.

It is important to cite here that there have been limited studies illuminating the Hyperion data exploitation for sub-pixel mineral investigation such as Magendran and Sanjeevi, 2013 applied Linear Spectral Unmixing (LSU) on calibrated Hyperion data for iron ore abundance mapping; Zadeh et al., 2013 discriminated and mapped the diagnostic hydrothermal alteration minerals viz., biotite, muscovite, illite, kaolinite, goethite, hematite, jarosite, pyrophyllite and chlorite etc. A partial sub-pixel method Mixture Tuned Matched Filtering (MTMF) was implemented on calibrated Hyperion dataset to derive the abundance map of each mineral.

Spatial resolution of the remotely sensed data play a crucial role and should be considered in mineral mapping. It is common that a pixel contain two or more minerals may containing spectral signature of all minerals present in a pixel, which causes mixing of spectral feature and hence the pixel contains less diagnostic spectral signature for particular target and yield less classification accuracy. So, a key attention should be given particularly while discussing about sub-pixel level feature extraction from such datasets. Generally, most of pixels are mixed class type due to the coarse spatial resolution of Hyperion sensor (Kumar et al., 2010). Because of its high spectral resolution and immense atmospheric attenuations, signal detected by a sensor in to a single pixel is frequently a combination of numerous disparate signals hence the actual spectral signature of material get altered. Due to low Signal to Noise Ratio (SNR) and higher sensitivity to noise, the quality of information retrieved from Hyperion image immensely gets affected. A serious concern coupled with these disparate signals is that the interferers are generally unknown in nature and cannot be identified from scene (Ren and Chang, 2000). The utility of several unmixing algorithms such as LSU, Matched Filtering (MF) and MTMF etc were well demonstrated by for sub-pixel target detection (Magendran and Sanjeevi, 2013; Molan et al., 2013; Zadeh et al., 2013; Zhang et al., 2014) but still these algorithms are not effective in minimizing the effect of interferences on the spectral mapping. In this study a hybrid unmixing algorithm i.e. MTTCIMF developed by Jin et al., 2009 was implemented on processed Hyperion data for sub-pixel mineral investigation. The algorithm combines MTMF and

* Corresponding author. 
TCIMF target detectors which offers opportunity to provide target as well as non-target information for improved sub-pixel target detection. Both MTMF and TCIMF are effective spectral matching techniques and widely used for hyperspectral target detection but the performance of target detectors get enhanced while computes as combined algorithm (Ren and Chang, 2000; Jin et al., 2009). MTMF uses MNF transformed bands to perform MF and it adds an infeasibility image to reduce the number of false positives whereas TCIMF is constrained to eliminate the response of non-targets and minimization of interfering effects to improve the efficiency of spectral mapping. Therefore, MTTCIMF algorithm can perform three simultaneous process i.e. eliminating the response of non-target (interference or unwanted signals), applying finite impulse filter and add infeasibility image to reduce the falsely mapped pixels.

The most common procedure adopted in the evaluation of hyperspectral analysis is done by using portable spectroradiometer and/or geochemical laboratory experiments. However, such procedure could be difficult in the hostile conditions or where such facilities are not easily accessible. With these concerns, a virtual verification (King and Clark, 2000) method has been adopted to evaluate the hyperspectral analysis results. This method uses directly image information to evaluate the result and could be very effective where accessing of such facilities are not possible. experiments. It is pertinent to mention here that utilization of MTTCIMF algorithm for Hyperion data analysis is not described so far. To the best of our knowledge rare publication available for the selected area as per as sub-pixel mineral mapping in concern, which clearly explain the need of study.

\section{Study Area}

The study area (Figure 1) is situated in the southern part of Rajsamand district of Rajasthan province, India with latitude and longitude ranging from $24^{\circ} 39^{\prime} 17.4^{\prime \prime}$ to $24^{\circ} 53^{\prime} 3.1^{\prime \prime} \mathrm{N}$ and $73^{\circ} 40^{\prime} 31.9^{\prime \prime}$ to $73^{\circ} 48^{\prime} 1.5^{\prime \prime} \mathrm{E}$ respectively. The area is chosen for study because of its geological richness, availability of suitable Hyperion scene and arid to semi-arid climatic conditions. The common litho-units (Figure 1) found here are synsedimentional basic volcanics, migmatite, gneiss, quartzite, phyllite, greywacke, felspathised, biotite, calc and mica schist of different geological age (Gupta et al., 1981; Sinha-Roy et al., 1993). The area is endowed with several metallic and non-metallic mineral deposits such as lead, zinc, copper, rock phosphate, limestone and dolomite etc (Roy et al., 1998). Since, the area is in hostile mountainous terrain where field based survey could be very difficult at initial stage nevertheless hyperspectral based study could offer valuable information in the form of distribution of surface minerals at sub-pixel level to geological and exploration community for further investigation.

Therefore, the main objective of this study is investigating the feasibility of Hyperion data for sub-pixel surface mineral mapping using MTTCIMF algorithm in arid and mountainous region of southern Rajsamand with limited lab and/or field

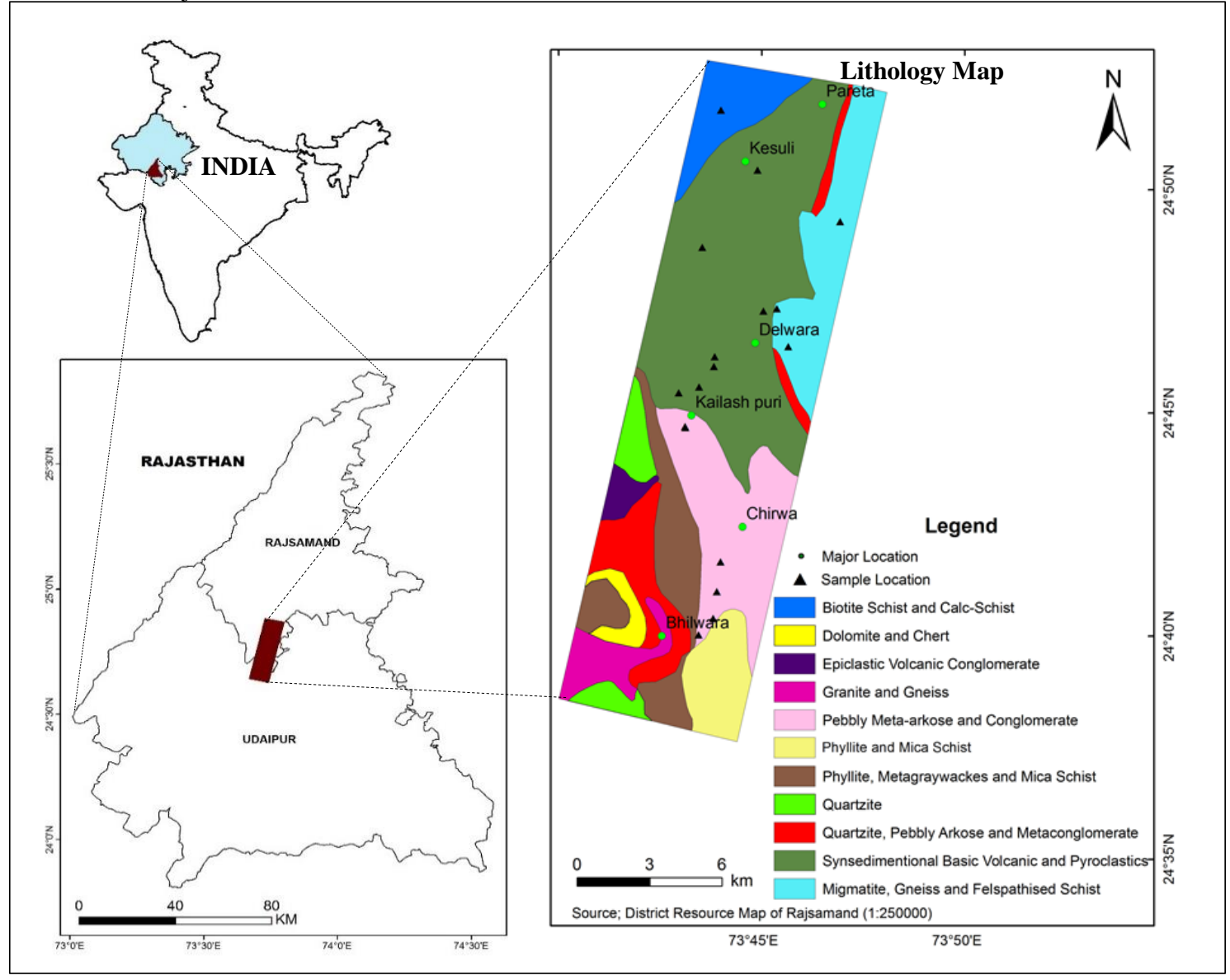

Figure 1. Location and Lithology map (redrawn after Gupta et al., 1981) with sample and major location in study area 


\section{Methodology}

\subsection{Data Sets}

The EO-1 Hyperion image of January 2004 was used to study the spatial distribution of surface mineral at sub-pixel level. The image consist of 224 spectral channels in the wavelength ranges 400-2500 nm of electromagnetic spectrum with the spectral and spatial resolution of $10 \mathrm{~nm}$ and $30 \mathrm{~m}$ respectively. A cloud free spatial subset of original image was selected for processing. Geological map of Rajsamand district of Rajasthan (scale: 1:250000) was referred as lithological guide and also used in representative rock sample collection from the study area. 25 rock samples were collected from several litho units and studied with Analytical Spectrometer Device (ASD) FiledSpec4 in wavelength ranges $350-2500 \mathrm{~nm}$ mineral detection. In the present study software packages such as ENVI 4.8 and ArcGIS 9.3 was used for hyperspectral image processing and creation of GIS layers respectively.

\subsection{Hyperion Data Processing}

The Hyperion Level 1R (i.e. radiometric corrected) image consist of 242 bands was used as raw data for processing. 169 calibrated bands were considered for further processing whereas rest of bands were uncalibrated and diversely affected by atmospheric attenuations were eliminated. These 169 bands were subjected to preprocessing i.e. removal of vertical strips, cluster of bad pixels, and atmospheric attenuations using Fast Line of Sight Atmospheric Spectral Hypercubes (FLAASH) of ENVI 4.8 to extract actual reflectance value of each pixel. A standard Hyperspectral data processing procedure outlined in Kruse, 1997 i.e. preprocessing, data reduction, Pixel Purity Index (PPI), endmember selection, target detection or mapping is followed. The Hyperion datasets have got significant limitations in the form of noise and dimensionality, to recoup these limitations minimum noise fraction (MNF) transformation coupled with pixel purity index (PPI) and endmember extraction were incorporated. First $20 \mathrm{MNF}$ bands consisting of more information and less noise were used to compute PPI with the iterations and threshold of 15000 and 2.5 respectively to derive the spectrally pure pixels. These pixels preserve better spectral characteristics rather than non-pure pixel and used in the endmember extraction. In this study endmembers were derived from individual pure pixel rather than considering the mean of similar pixels, to avoid mixing of endmember/target to possible extent. Since the study's goals is sub-pixel mineral mapping which requires possible pure endmember to represent an individual mineral for accurate target detection and mapping. This approach could provide an advantage of avoiding mixing of endmembers and hence may yield better accuracy in mineral mapping. These endmembers were then assessed with USGS mineral spectral library available in ENVI 4.8 for mineral identification. Nevertheless, a preliminary field visit was also carried to understand the geology of the area and to collect rock sample from each possible litho units. Lab spectra of each rock samples obtained from Analytical Spectrometer Device (ASD) FieldSpec 4 in the wavelength of $350-2500 \mathrm{~nm}$ at sampling interval of 1.4 nm @350-1050 nm and 2 nm @1000-2500 nm in normal condition to detect major constituent of samples by spectral inspection to make sure the existence of minerals in the ground. Finally, illite, montmorillonite, dolomite, phlogopite and chlorite minerals were selected as endmembers. Selection of these endmembers were based on following two criteria i.e. pixel and rock sample's spectra must show the diagnostic spectral signature and also commonly found in the area. However, the geolocation of rock samples and their corresponding pixel' spectra were not considered to make any evaluation or correlation because of coarser spatial resolution of Hyperion data. Since, the study does not uses geochemical analysis to detect minerals therefore a key consideration were given on spectral inspection for mineral detection of both field rock samples and image endmembers.

\subsection{Sub-pixel Mineral Mapping}

A hybrid unmixing algorithm i.e. MTTCIMF was implemented on processed Hyperion data for sub-pixel surface mineral mapping. The algorithm require MNF bands of reflectance image, desired and undesired target spectra as basic input to generate distribution map of given endmembers. In this study, image spectra of illite, montmorillonite, dolomite, phlogopite and chlorite minerals were given as target whereas three noisy spectra such as spectrum of or near pixel of shadow, dry vegetation and water body were given as non-target. These noisy spectra have better possibility to provide best information about unwanted signals or noises and least information of targets. The main purpose of giving non-target spectra here is to minimize the effect of disparate signals on the spectral mapping algorithm. The target detection wizard of ENVI 4.8 software package was used to implement this algorithm. Results of this algorithm are two sets of gray images for each endmember including TCIMF score and infeasibility image. Correctly mapped pixels contains TCIMF score above than background distribution around zero and a low infeasibility value exported as correctly classified target minerals from each rule and infeasibility images to generate distribution map of endmembers.

\section{Results and Discussion}

\subsection{Endmember Extraction}

Five minerals (Figure 2) viz. illite, montmorillonite, dolomite, phlogopite and chlorite were selected as endmembers derived from individual pure pixel of reflectance Hyperion imagery to avoid mixing of two or more minerals to possible extent. The spectra of these minerals shows diagnostic spectral signature which is similar to lab spectra of field rock samples as well as USGS mineral spectral library. The spectral inspection of both lab and image spectra was carried with USGS mineral spectral library available in ENVI 4.8 software package. The spectral plots of illite (Figure 2(a)) and montmorillonite (Figure 2(b)) show a diagnostic absorption feature at $2.2 \mu \mathrm{m}$ due to $\mathrm{Al}-\mathrm{OH}$ vibration. The spectral plots of dolomite (Figure 2(c)) displays a diagnostic absorption feature at $2.31 \mu \mathrm{m}$ due to $\mathrm{CO}_{3}$ and $\mathrm{Mg}$ molecules. It should be noticed here that USGS spectra of dolomite shows more absorption depth compared to image and lab spectra of dolomite caused by higher concentration of $\mathrm{CO}_{3}$ and $\mathrm{Mg}$ molecules than image pixel and lab sample. The spectral plots of phlogopite (Figure 2(d)) shows the diagnostic absorption feature at $2.3 \mu \mathrm{m}$ due to $\mathrm{Mg}-\mathrm{OH}$ molecules. A small absorption feature is found near 2.1 to $2.2 \mu \mathrm{m}$ caused due to secondary minerals. The spectral plots of chlorite (Figure 2(e)) displays a diagnostic absorption feature at $2.35 \mu \mathrm{m}$ due to $\mathrm{Mg}-\mathrm{OH}$ molecules. Both image and USGS spectra of chlorite show absorption feature near $0.7 \mu \mathrm{m}$ due to presence of $\mathrm{Fe}^{2+}$ but does not found in lab spectra. It is important to notice here that one or more minerals shows their diagnostic absorption in same or near wavelength region but still could be differentiated by analyzing their overall spectral curve. However, in present case illite and montmorillonite as well as dolomite and phlogopite display their diagnostic absorption feature at 2.2 and near $2.3 \mu \mathrm{m}$ respectively and easily differentiated by analyzing the overall spectral curve of these minerals. The most diagnostic spectral signature of these minerals falls in the wavelength ranges of 2.2 to $2.35 \mu \mathrm{m}$ which 
mainly caused by $\mathrm{Al}-\mathrm{OH}$ and $\mathrm{CO}_{3}, \mathrm{Mg}-\mathrm{OH}$ molecules. These minerals also closely associated with either argillic or pyrophyllite zone of hydrothermal alteration and mineralization.

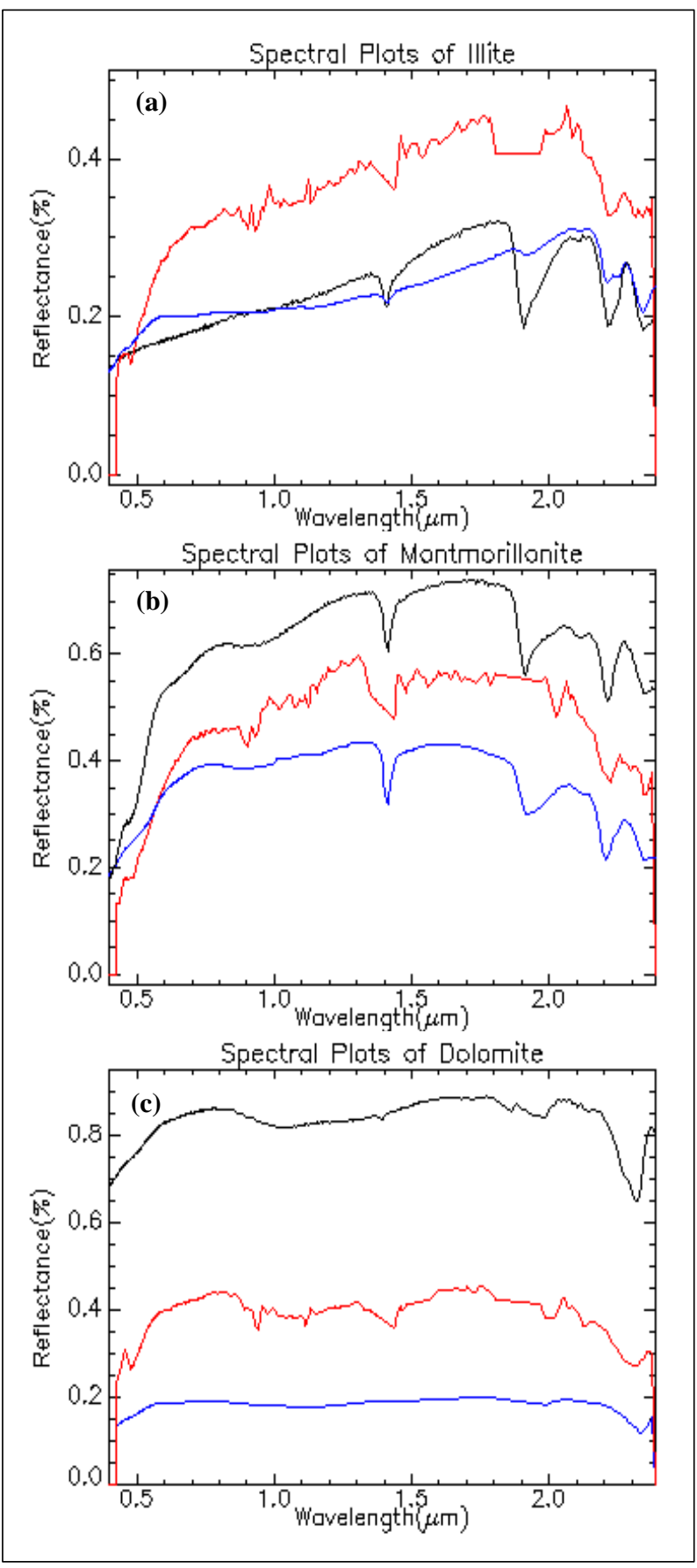

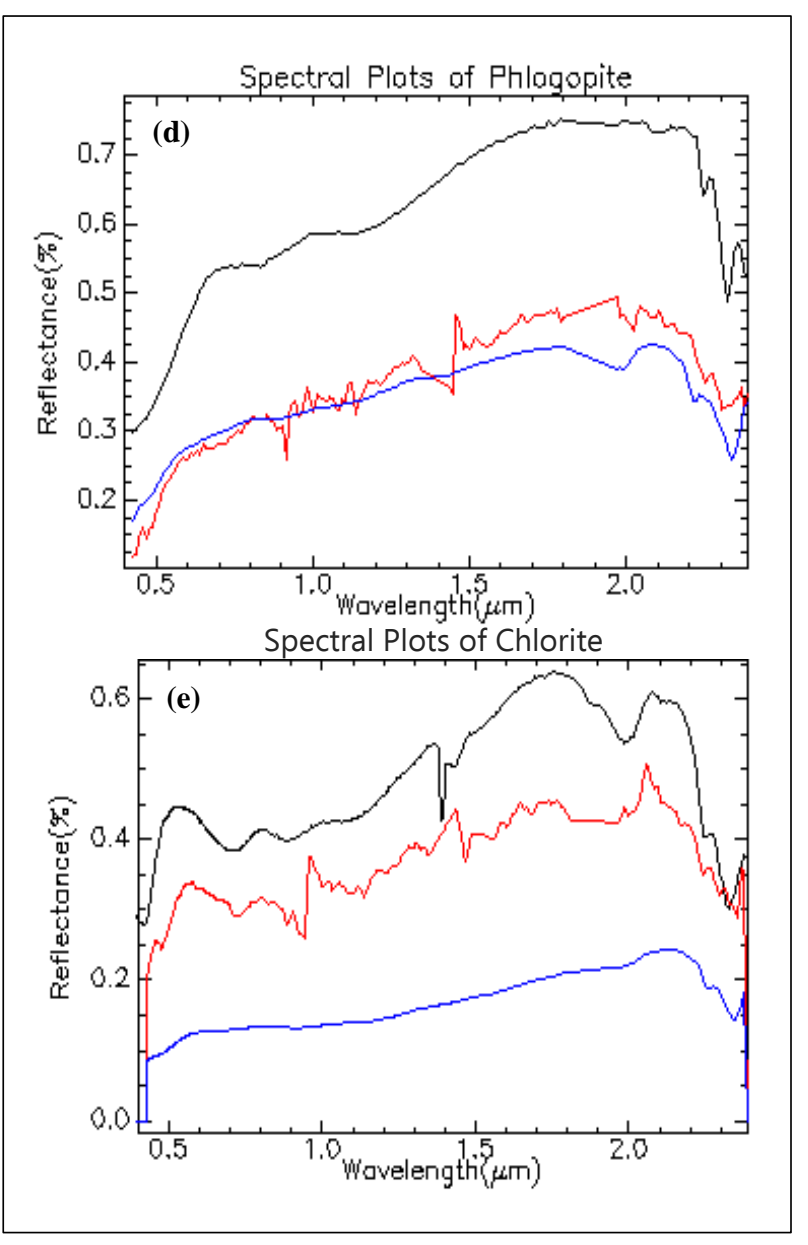

Figure 2. The spectral plots of detected minerals (endmembers). (a) spectral plots of illite, (b) spectral plots of montmorillonite, (c) spectral plots of dolomite, (d) spectral pots of phlogopite, (e) spectral plots of chlorite. Red line: image spectra, blue line: lab spectra, black line USGS spectra. In image spectra there was no bands in the wavelength region of 1.4 and 1.9 due to water absorption.

\subsection{Sub-pixel Mineral Mapping using MTTCIMF}

Results of MTTCIMF algorithm produce set of rule images (Figure 3) corresponding to TCIMF score and infeasibility values for each endmembers. These rule images are in grey color where bright and dark tone represent target and background respectively. Correctly mapped pixels contains TCIMF score above than background distribution and a low infeasibility value exported as correctly classified target minerals from each rule and infeasibility images to generate sub-pixel mineral map (Figure 4) of endmembers. A visual interpretation of rule images and mineral distribution map illustrates an overall distribution of mineral with the respect to lithology of the area. Most of illite found in synsedimentional basic volcanics, gneiss and schist. Montmorillonite dominantly found in ridges and near the contact boundaries of synsedimentional basic volcanics and migmatites, gneiss and schist in poorly drainage region. Dolomite is dominantly found in phyllite and mica schist. Phlogopite and chlorite is found in the area of biotite-calc schist, volcanic rocks and felspathised schist. The summary of sub-pixel mineral map is given in Table 1 . 


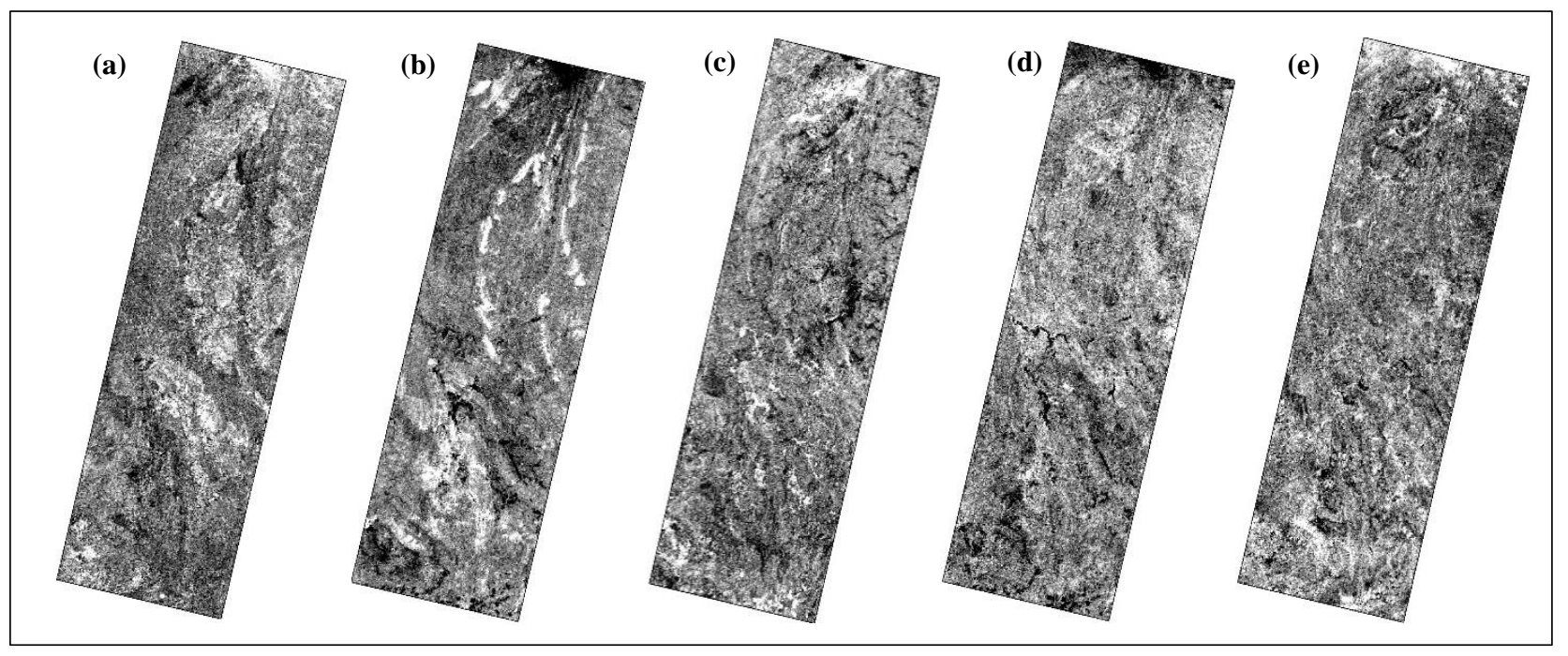

Figure 3. TCIMF rule images of each detected surface minerals derived from MTTCIMF algorithm. (a) illite, (b) montmorillonite, (c) dolomite, (d) phlogopite, (e) chlorite.

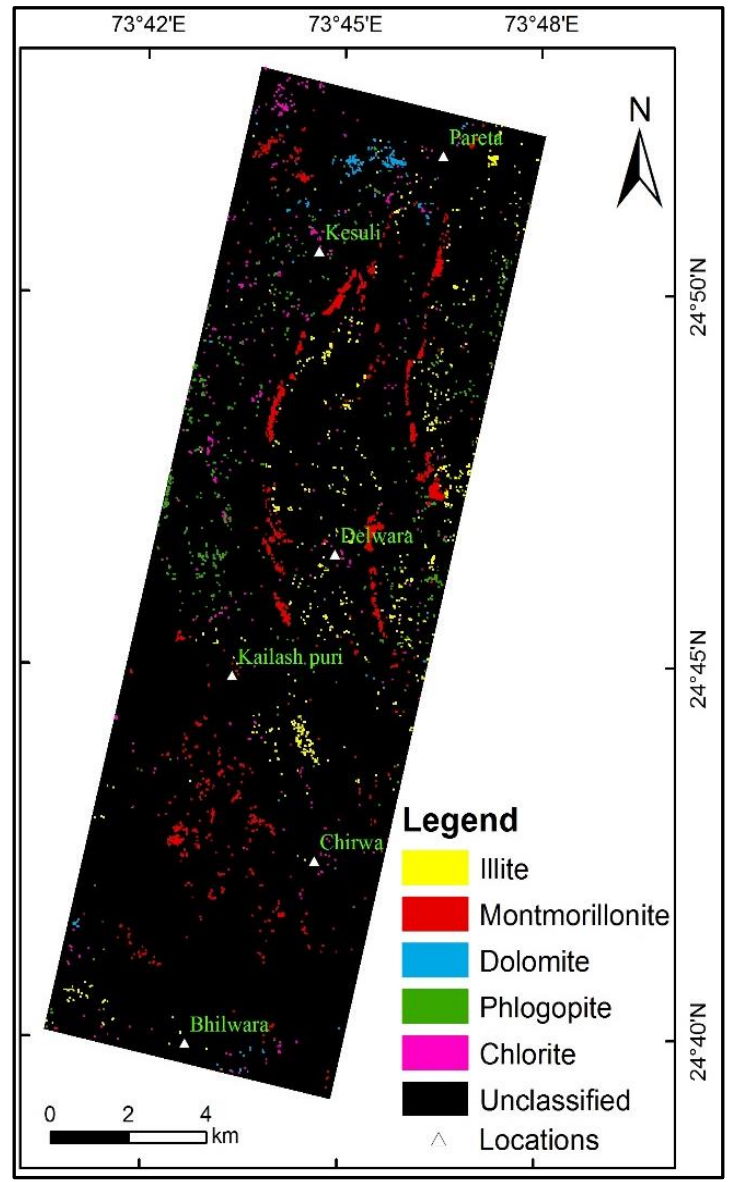

Figure 4. Sub-pixel surface mineral map derived from MTTCIMF algorithm.
Table 1. Summary of sub-pixel mineral map

\begin{tabular}{|c|c|}
\hline Minerals & Total classified pixels \\
\hline Illite & 794 \\
\hline Montmorillonite & 1992 \\
\hline Dolomite & 228 \\
\hline Phlogopite & 439 \\
\hline Chlorite & 668 \\
\hline
\end{tabular}

\section{Accuracy assessment}

In this study, validation of results were carried in to two part i.e. confirmation of detected mineral and evaluation of classified image. Confirmation of detected minerals was done by visual interpretation of spectral signature and overall spectral curve with the help of USGS mineral spectral library. However, there was some dissimilarity between spectra of lab and library were found due to the difference in quality of sample whereas dissimilarity between image spectra and lab or spectral library was found due to coarser spatial resolution of the image data. Since, there was no access to any portable spectroradiometer and geochemical analysis therefore, to evaluate the accuracy of classified image a virtual verification method has been adopted. This approach is successfully used by Molan et al., 2013 to assess the MF classification results of mineral map. To evaluate the accuracy of classified image, 25 pixel 'spectra of each class were generated randomly and then those spectra were verified with endmembers given as target by visual spectral inspection. For example, a pixel which is classified as illite and if the actual reflectance spectra of that corresponding pixel is similar to illite spectra then it is considered as correctly mapped pixel else spectra shows similarity with another class endmember means pixel is falsely mapped and assign to that class endmember. Same procedure was followed for all pixels selected for verification and confusion matrix (Table 2) (Congalton, 1991) was formulated to compute overall accuracy (68\%) and kappa coefficient (0.6). From the confusion matrix and spectral profiles of minerals, it could be refereed that mineral having similar spectral signatures yields less accuracy while mineral having distinct spectral signatures yields greater accuracy for example, phlogopite and chlorite shows similar spectral feature while 
dolomite spectra is distinct compared to other endmembers hence yield minimum and maximum accuracy respectively.

Table 2. Confusion matrix of classified image

\begin{tabular}{|c|c|c|c|c|c|c|c|c|}
\hline & Illite & Montmorillonite & Dolomite & Phlogopite & Chlorite & Total & $\begin{array}{c}\text { Omission } \\
(\%)\end{array}$ & $\begin{array}{c}\text { Commission } \\
(\%)\end{array}$ \\
\hline Illite & 17 & 3 & 2 & 3 & 1 & 26 & 35 & 30 \\
\hline Montmorillonite & 7 & 18 & 1 & 2 & 1 & 29 & 38 & 24 \\
\hline Dolomite & 0 & 2 & 20 & 2 & 3 & 27 & 26 & 18 \\
\hline Phlogopite & 1 & 2 & 0 & 16 & 6 & 25 & 36 & 36 \\
\hline Chlorite & 0 & 0 & 2 & 2 & 14 & 18 & 22 & 61 \\
\hline Total & 25 & 25 & 25 & 25 & 25 & 125 & & \\
\hline Mapping accuracy (\%) & 51 & 50 & 62.5 & 47 & 47 & & & \\
\hline User accuracy (\%) & 65 & 62 & 74 & 64 & 78 & & & \\
\hline Producer accuracy (\%) & 68 & 72 & 80 & 64 & 56 & & & \\
\hline Overall accuracy = 68 \% ; Kappa coefficient = 0.6 & \multicolumn{7}{l}{} \\
\hline
\end{tabular}

\section{Conclusion}

The present study investigated the feasibility of Hyperion data for sub-pixel mineral mapping using MTTCIMF algorithm in arid and mountainous region with limited lab and/or field experiments. The endmember extraction from individual pure pixel was quiet useful to deriving target minerals such as illite, montmorillonite, dolomite, phlogopite and chlorite. Generally, these minerals are closely associated with either argillic or pyrophyllite zone of hydrothermal alteration and mineralization. The overall accuracy $(68 \%)$ and kappa coefficient $(0.6)$ demonstrate the efficiency of algorithm for sub-pixel target detection. A detailed mineral distribution map could provide better understanding of possible mineralization in the area for detailed field investigation. However, the algorithm does not produce high accuracy as per as its efficiency is concern, mainly due to similarity between interclasses and limited SNR of the Hyperion image.

The study also explains that even though a routine procedure of hyperspectral data exploitation require sophisticated portable spectroradiometer and geochemical analysis etc but still freely available these high spectral resolution data could be used to improve the understanding and management of earth' surface without sophisticated equipment as shown in the study. In future, upcoming spaceborne hyperspectral sensors with improved SNR and resolutions could provide an enhanced perspective of earth' surface.

\section{References}

Breck, R., (2003). EO-1 User Guide, Version 2.3., University of Cincinnati.

Clark, R.N., 1999. Spectroscopy of rocks, and minerals and principles of spectroscopy. In: Rencz, A.N., Ryerson, R.A. (Eds.), Remote Sensing for the Earth Sciences, Manual of Remote Sensing, third ed. John Wiley \& Sons, New York, NY, pp. 3-58.

Congalton, R.G. 1991. A review of assessing the accuracy of classifications of remotely sensed data. Remote Sensing of Environment 37, pp. 35-46.

Farifteh, J., Nieuwenhuis, W., and Melendez, E.G., 2013. Mapping spatial variations of iron oxide by product minerals from EO-1 Hyperion. International Journal of Remote Sensing 34:2, pp. 682-699.

Garcia-Haro, F.J., gilabert, M.A., and Melia, J., 1999. "Extraction of endmembers from spectral mixture". Remote Sensing of Environment 68, pp. 237-257.

Gupta, S.N., Arora, Y.K., Mathur, R.K., Balluddin,I.Q., Prasad, B., Sahai, T.N. and Sharma, S.B., 1981. Lithostatigraphic map of Aravalli region, South-eastern Rajasthan and northern Gujrat, Geological Survey of India, Hyderabad.

Hunt, G.R. 1977. Spectral signatures of particulate minerlas in the visible and near infrared. Geophysics 42, pp. 501-513

Jafari, R., and Lewis, M.M., 2012. Arid land characterisation with EO-1 Hyperion hyperspectral data. International Journal of Applied Earth Observation and Geoinformation 19, pp. 298307.

Jin, X., Paswaters. S., and Cline, H., 2009. A comparative study of target detection algorithms for hyperspectral imagery. Proc. SPIE 7334, Algorithm and Technologies for Multispectral, Hyperspectral, and Ultraspectral Imagery XV, 73341W.

King, T.V.V., and Clark, R.N., 2000. Verification of remotely sensed data. In: Kuehn, F., King, T., Hoerig, B., Pieters, D. (Eds). Remote Sensing for Site Characterization. Springer, Berlin, pp. 59-61.

Kruse, F.A., Perry, S.L., and caballero, A., 2006. District level mineral survey using airborne hyperspectral data, Los Menucos, Argentina. Annals of Geophysics 49, n.1, pp. 83-92.

Kumar, A.S., Keerthi, V., Manjunath, A.S., Werff, van der. H., and Meer van der. F., 2010. Hyperspectral image classification by variable interval spectral average and spectral curve matching combined algorithm. International Journal of Applied Earth Observation and Geoinformation 12, pp. 261-269.

Kusuma, K.N., Ramakrishnan,D., and Pandalai, H.S., 2012. Spectral pathways for effective delineation of high grade bauxites: a case study from the Savitri river Basin, Maharastra, India, using EO-1 Hyperion data". International Journal of Remote Sensing 33:22, pp. 7273-7290. 
Magendran, T., and Sanjeevi, S., 2013. Hyperion image analysis and linear spectral unmixing to evaluate the grades of iron ores in the part of Noamundi, Eastern India. International Journal of Applied Earth Observation and Geoinformation 26, pp. 413426.

Molan, Y.E., Refali, D., and Tarashti, A.H., 2013. Mineral mapping in the Maherabad area, eastern Iran, using Hymap remote sensing data. International Journal of Applied Earth Observation and Geoinformation 27, pp. 117-127.

Ren, H., and Chang. C., 2000. Target-constrained interferenceminimized approach to sub-pixel target detection for hyperspectral images. Opt. Eng. 39(12), pp. 3138-3145.

Rowan, L.C., Simpson, C.J., and Mars, J.C., 2004. Hyperspectral analysis of the ultramafic complex and adjacent lithologies at Mordor, NT, Australia. Remote Sensing of Environment 91, pp. 419-431.

Roy, S.S., Malthottra, G., and Mohanty, M., 1998. Geology of Rajasthan. Bangalore: Geology Society of India, Hyderabad.

Sinha-Roy, S., Mohanty, M. and Guha, D.B. 1993. Banas Dislocation Zone in Nathdwara-Khamour Area, Udaipur district, Rajasthan and its suignificance on the basement-cover relations in the Aravalli fold belt. Current Science. 65(1), pp. 68-72.

Zadeh, M.H., Tangestani, M.H., Roldan, F.V., and Yusta, I., 2013. Sub-pixel mineral mapping of a porphyry copper belt using EO-1 Hyperion data. Advances in Space Research 53, pp. 440-451.

Zhang, X., and Li, X., 2014. Lithological mapping from hyperspectral data by improved use of spectral angle mapper. International Journal of Applied Earth Observation and Geoinformation 31, pp. 95-109. 